\title{
Mechanism of Isomerization and Methyl Migration in Heterobimetallic Re-Ir Complexes: Experimental and DFT Study
}

\author{
Kothanda Rama Pichaandi, ${ }^{[\mathrm{a}]}$ Lara Kabalan, ${ }^{[\mathrm{b}]}$ Sabre Kais, ${ }^{[\mathrm{a}],[\mathrm{b}]}$ Mahdi M. Abu-Omar*a],[c] \\ ${ }^{a}$ Brown Laboratory, Department of Chemistry, Purdue University, 560 Oval Drive, West \\ Lafayette, IN 47907, USA \\ ${ }^{\mathrm{b}}$ Qatar Environment and Energy Research Institute, Hamd Bin Khalifa University, Qatar \\ Foundation, PO Box 5825, Doha, Qatar \\ ${ }^{\mathrm{c}}$ School of Chemical Engineering, Purdue University, Forney Hall of Chemical Engineering, \\ 480 Stadium Drive, West Lafayette, IN 47907, USA \\ * Corresponding author e-mail: mabuomar@purdue.edu
}

\section{Supporting Information}

\section{Table of Contents}

Index Page

Figure S1. ${ }^{1} \mathrm{H}$ NMR (expanded region) comparison before, during the progress $\quad \mathrm{S} 2$ of reaction and at the end of reaction between 1 and $\mathrm{CD}_{3} \mathrm{OD}$.

Figure $\mathrm{S} 2 .{ }^{31} \mathrm{P}\left\{{ }^{1} \mathrm{H}\right\}$ NMR comparison before, during the progress of reaction $\quad \mathrm{S} 3$ and at the end of reaction between 1 and $\mathrm{CD}_{3} \mathrm{OD}$.

Figure S3. ${ }^{1} \mathrm{H}\left\{{ }^{31} \mathrm{P}\right\}$ NMR (expanded region) of 3 at $201{ }^{\circ} \mathrm{K}$ showing the van $\mathrm{S} 4$ der Waals force of attraction between rhenium metal center and the tert-butyl groups attached to $\mathrm{P}$ atom of ligand. 


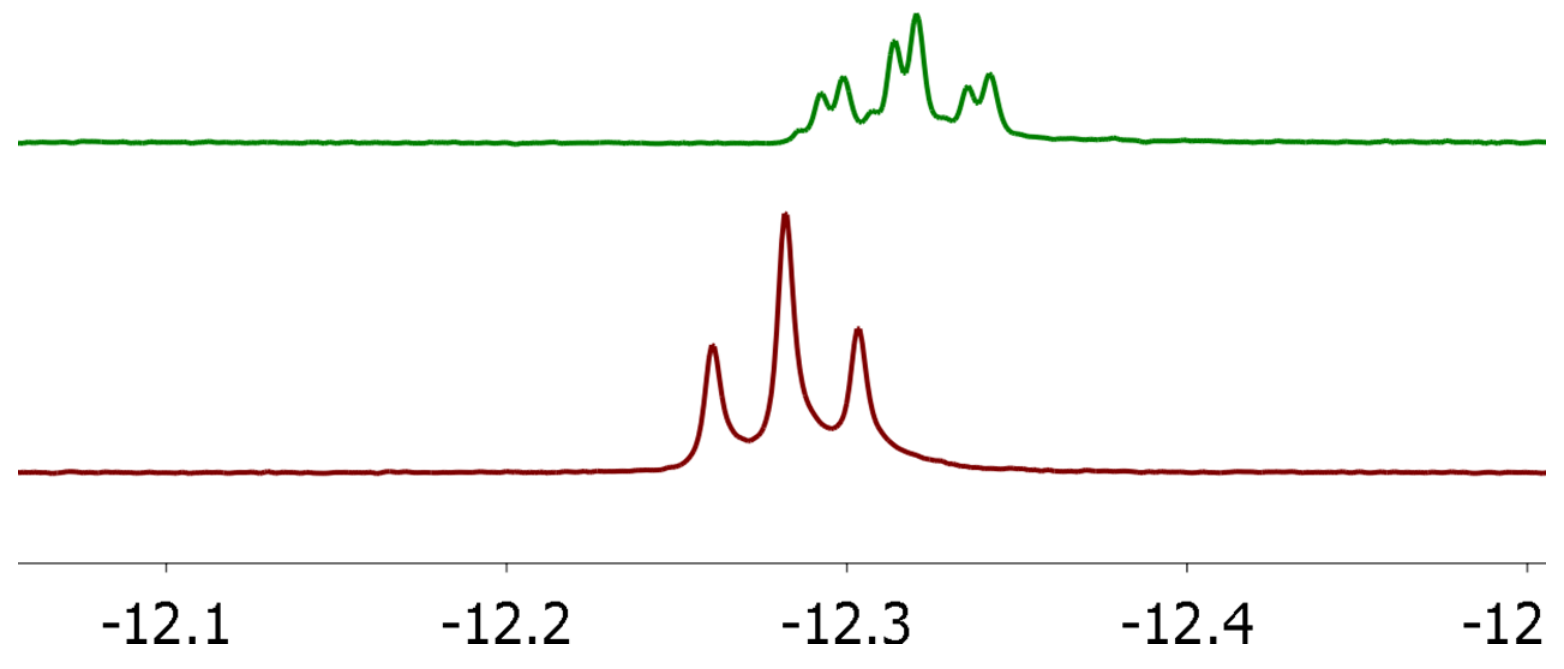

Fig S1. ${ }^{1} \mathrm{H}$ NMR (Ir-H expanded region) comparison before adding $\mathrm{CD}_{3} \mathrm{OD}$ (bottom), during the progress of reaction (middle) and at the end of reaction (top) between $\mathbf{1}$ and $\mathrm{CD}_{3} \mathrm{OD}$. 


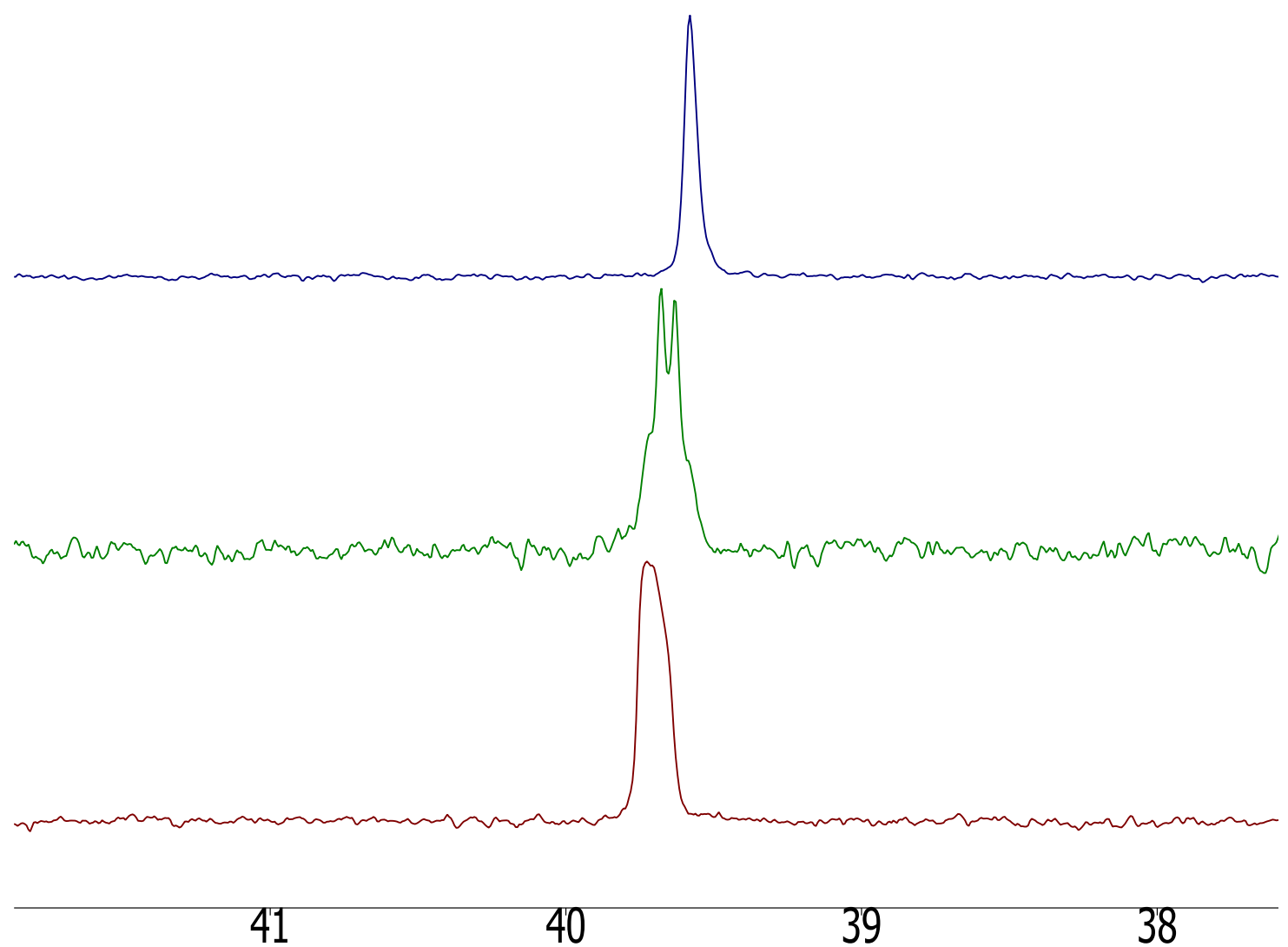

Fig S2. ${ }^{31} \mathrm{P}\left\{{ }^{1} \mathrm{H}\right\}$ NMR comparison before adding $\mathrm{CD}_{3} \mathrm{OD}$ (bottom), during the progress of reaction (middle) and at the end of reaction (top) between 1 and $\mathrm{CD}_{3} \mathrm{OD}$. 


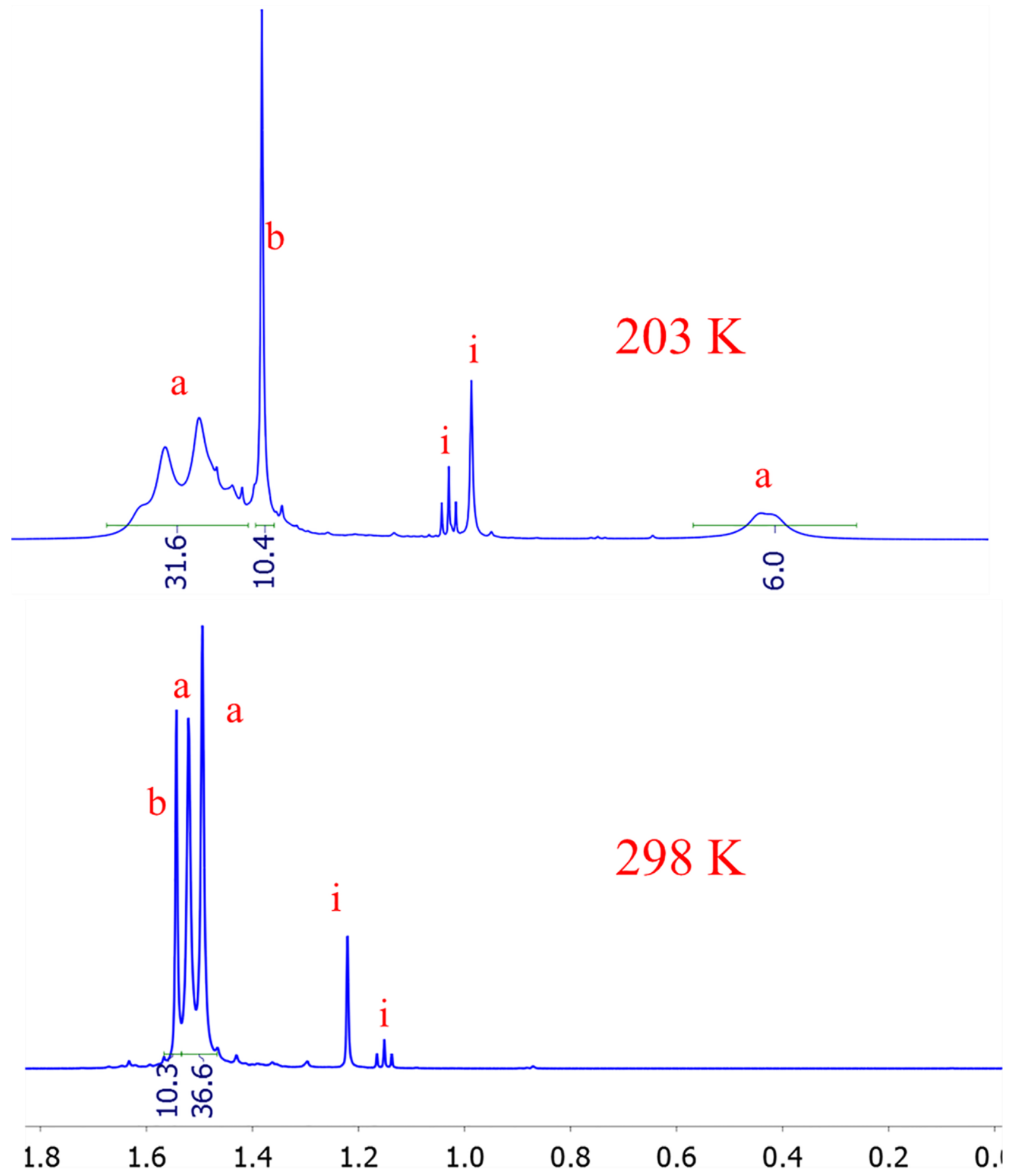

Figure S3. ${ }^{1} \mathrm{H}\left\{{ }^{31} \mathrm{P}\right\}$ NMR (expanded region) of 3 at $203 \mathrm{~K}$ (top) in comparison with $298 \mathrm{~K}$ (bottom) showing Van der Waals force of attraction between rhenium metal center and the tertbutyl groups attached to the $\mathrm{P}$ atom of the ligand $\mathrm{a}=$ tert-butyl- $\mathrm{P}(\mathbf{3}) \mathrm{b}=$ tert-butyl (isocyanide, 3), i = impurity. 